\title{
Characterization of the Race Structure of Leptosphaeria maculans Causing Blackleg of Winter Canola in Oklahoma and Kansas
}

\author{
Claudia Diaz, Felipe Cevallos, and John Damicone ${ }^{\dagger}$ \\ Department of Entomology and Plant Pathology, Oklahoma State University, Stillwater, OK 74078
}

\begin{abstract}
Blackleg, caused by the fungus Leptosphaeria maculans, is a widespread disease of winter canola (Brassica napus) in Oklahoma and Kansas. Deployment of genetic resistance is the primary strategy for managing blackleg. Resistance genes $(R / m)$ in canola interact with avirulence genes in the fungus (AvrLm) in a gene-for-gene manner. Little is known about the diversity and frequency of avirulence genes and the race structure in the region. Isolates of Leptosphaeria spp. were collected from diseased leaves in nine counties in Oklahoma and one county in Kansas from 2009 to 2013. Based on pathogenicity and PCR amplification of mating type and species-specific internal transcribed spacer loci, most isolates $(n=90)$ were $L$. maculans. The presence of avirulence genes was evaluated using phenotypic interactions on cotyledons of differential cultivars with $R \operatorname{lm} 1, R \operatorname{lm} 2$, Rlm3, and Rlm4 and amplification of AvrLm1, AvrLm4-7, and AvrLm6

by PCR. The avirulence alleles AvrLm6 and $A v r L m 7$ were present in the entire L. maculans population. AvrLml was found in $34 \%$ of the population, AvrLm2 in 4\%, and AvrLm4 in only 1\%. A total of five races, defined as combinations of avirulence alleles, were identified that included AvrLm1-2-6-7, AvrLm2-6-7, AvrLm4-6-7, AvrLm1-6-7, and AvrLm6-7. Races virulent on the most Rlm genes, AvrLm1-6-7 at $32 \%$ and AvrLm6-7 at $62 \%$, were predominant. Defining the avirulence allele frequency and race structure of $L$. maculans should be useful for the identification and development of resistant cultivars and hybrids for blackleg management in the region. The results suggest that $R \operatorname{lm} 6$ and $R \operatorname{lm} 7$ would be effective, although their deployment should be integrated with quantitative resistance and cultural practices, such as crop rotation, that limit selection pressure on $\mathrm{Rlm}$ genes.
\end{abstract}

Winter canola (Brassica napus L.) is an increasingly important crop in the states of Oklahoma and Kansas. Since 2009 when statistics on winter canola production in the region were first reported, from 12,545 to 75,676 ha of the crop were harvested each year at a value of from $\$ 7.3$ to $\$ 42.3$ million/year (https://www.nass.usda. gov/). Blackleg disease, caused by the fungus Leptosphaeria maculans (Desm.) Ces. \& DeNot, is an economically important disease of oilseed rape and canola in most regions of the world where crop is grown (Rouxel and Balesdent 2005). The disease was first identified in Oklahoma in 2009 (del Río Mendoza et al. 2011) when it caused yield loss in several fields. Blackleg has since become widespread in the region.

Airborne ascospores from old crop stubble are considered the primary source of disease epidemics in canola (Rimmer and van den Berg, 2007). In addition, conidia produced in pycnidia on stubble have been trapped aerially (Guo and Fernando 2005) and shown to serve as the primary inoculum in Western Canada (Ghanbarnia et al. 2011). Spores released from crop stubble cause leaf spots on plants during periods of warm $\left(>20^{\circ} \mathrm{C}\right)$ wet weather after planting. The fungus grows from leaves into the base of the stem where it causes a stem canker during the ripening stage of crop development. Where susceptible cultivars of winter canola are grown and young plants are infected early (in the fall), stem cankers may completely girdle stems and cause lodging and stem death prior to harvest. When older plants are infected later in crop development (in the spring), incomplete girdling of affected stems occurs. Cankers that girdle $50 \%$

${ }^{\dagger}$ Corresponding author: J. Damicone; john.damicone@okstate.edu

Funding: This research was funded by the U.S. Department of Agriculture National Institute of Food and Agriculture Supplemental and Alternative Crops Competitive Grants Program, the Oklahoma Agricultural Experimental Station, and the Oklahoma Oilseed Commission.

The author(s) declare no conflict of interest.

Accepted for publication 8 April 2019.

(C) 2019 The American Phytopathological Society or more of the stem bases are thought to contribute to yield losses by reducing pod and seed development.

Blackleg is caused by two closely related species, L. maculans and L. biglobosa (Mendes-Pereira et al. 2003; Shoemaker and Brun 2001), which were previously classified as highly aggressive and weakly aggressive forms of $L$. maculans, respectively (Cunningham 1927; Petrie 1978; Shoemaker and Brun 2001). These species may share the same ecological niche and have similar epidemiology and infection strategies; however, they differ in symptoms, severity of the disease, cultural characteristics, and host-pathogen interactions (West et al. 2002). L. maculans is a highly specialized pathogen interacting in a gene-for-gene manner with $B$. napus. By contrast, $L$. biglobosa has not exhibited such specialized interactions (Vincenot et al. 2008).

Major gene resistance has been widely used to control blackleg (Delourme et al. 2006). Major gene resistance occurs as a genefor-gene interaction between $B$. napus and $L$. maculans, where the resistant phenotype depends on the presence of a major gene for resistance $(\mathrm{Rlm})$ in the plant and a corresponding avirulence $(\mathrm{AvrLm})$ gene in the pathogen (Balesdent et al. 2005; Marcroft et al. 2012). Conversely, the lack of a resistance gene in the plant or an avirulence gene in the pathogen results in a susceptible reaction and the expression of disease. To date, at least 14 major resistance genes have been identified (Rlm1 to Rlm11, LepR1 to LepR3) in Brassica species conferring resistance to L. maculans (Marcroft et al. 2012; Van de Wouw et al. 2014) and LepR3 and Rlm2 have been cloned (Larkan et al. 2013, 2015). Most of these genes have been positioned on B. napus linkage maps and are organized in clusters (Delourme et al. 2004, 2006). Of the corresponding avirulence genes conferring host specificity in L. maculans, AvrLm1, AvrLm4-7, AvrLm5-9, AvrLm6, AvrLm11, and AvrLmJ1/AvrLm5 have been cloned and sequenced (Balesdent et al. 2013; Fudal et al. 2007; Ghanbarnia et al. 2018; Gout et al. 2006; Parlange et al. 2009; Plissonneau et al. 2018; Van de Wouw et al. 2014).

For conceptualizing the variation of virulence and genetic interaction between $B$. napus and L. maculans, the phenotype interaction on a set of $B$. napus differential cultivars that included Westar, Glacier (Rlm2,3), and Quinta (Rlm1) was used to classify L. maculans isolates into pathogenicity groups (PGs) (Mengistu et al. 1991). The 
PG4 isolates were virulent on Westar, Glacier, and Quinta; PG3 isolates were avirulent on Quinta and PG2 isolates were avirulent on Glacier and Quinta. Isolates that were virulent on Westar and Quinta but not Glacier were later classified as PGT (del Río Mendoza et al. 2012; Kutcher et al. 2007). Avirulence on Westar discriminated $L$. biglobosa (PG1) from L. maculans. This PG system was initially valuable to detect virulence changes in pathogen populations; however, as new genes in the pathogen and host were described, the PG system of classification became inadequate because isolates with different avirulence alleles could be classified in the same group, and it is not intuitively interpreted (Kutcher et al. 2010a). Balesdent et al. (2005) proposed describing races of $L$. maculans by listing the $A v r$ allele composition of an isolate for which it has been characterized.

Resistance genes $(R l m)$ in B. napus have been characterized based on the genetic identification of corresponding avirulence alleles (AvrLm) in L. maculans (Rouxel and Balesdent 2005). Deployment of $B$. napus resistance genes has proven to be very effective in $L$. maculans populations that display the corresponding avirulence genes. However, the repeated planting of the cultivars with specific resistance genes has created high selection pressure on the pathogen population (Rouxel et al. 2003). As a result, the pathogen may adapt to resistance genes and overcome resistance relatively quickly (Dilmaghani et al. 2009). For example, the resistance gene Rlml was initially effective in France but was overcome three growing seasons later causing important economic losses (Balesdent et al. 2006; Rouxel et al. 2003). Similarly, the resistance gene LepR3 became ineffective 3 years after it was first deployed in Australia (Hayden et al. 2007; Li et al. 2003).

Knowledge of the race structure is crucial for detecting genotypes with the ability to overcome current specific resistance genes and choosing the best resistance sources to be used locally (Dilmaghani et al. 2009; Kutcher et al. 2010b). Using various sets of differential cultivars and amplification of avirulence genes with PCR, avirulence allele patterns and race structures of the pathogen have been

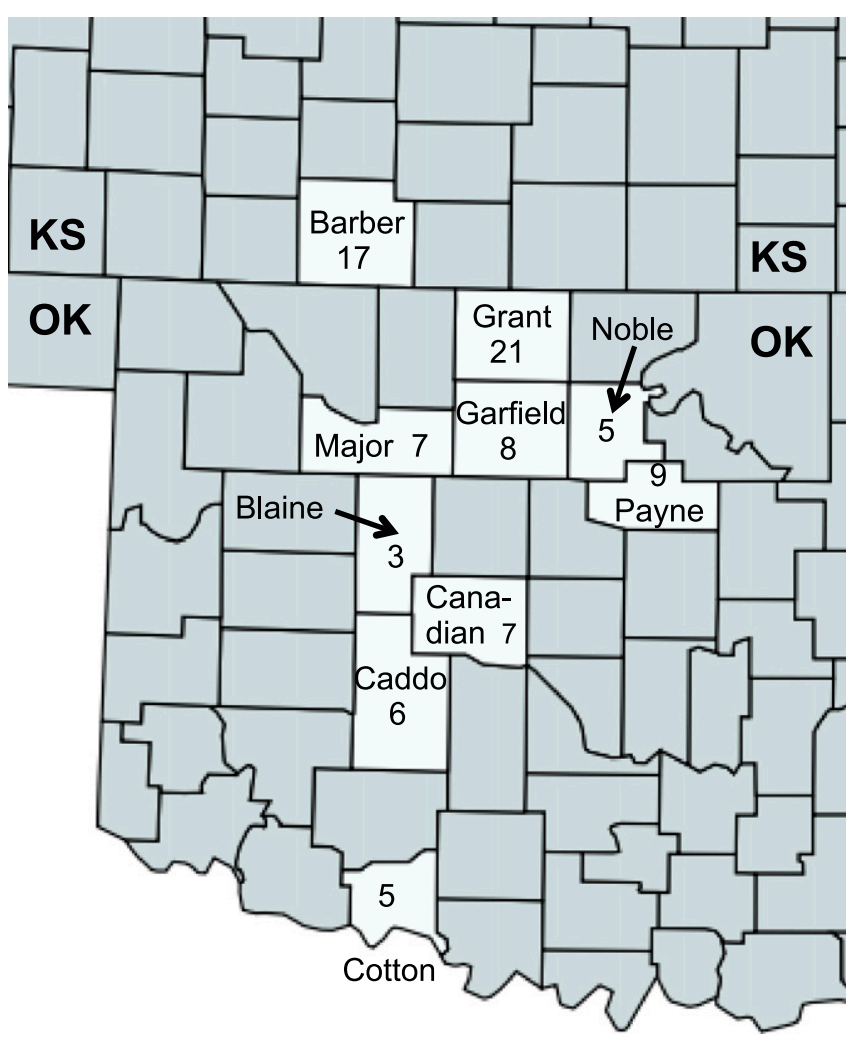

Fig. 1. Counties in the states of Oklahoma and Kansas where winter canola was sampled from 2009 to 2013 and the number of isolates of Leptosphaeria maculans collected ( $n=88$; the geographic origin of two isolates included in this study was unknown). described in Australia, in Germany and France in Europe, in Chile in South America, and in Mexico, Canada, and the southeastern United States in North America (Balesdent et al. 2005, 2006; Dilmaghani et al. 2009; Fernando et al. 2018). However, there is no information on the races of L. maculans in Oklahoma and Kansas. The objective of this study was to determine the race structure of $L$. maculans in the region using a combination of pathogenicity tests on B. napus differential cultivars and amplification of avirulence genes by PCR.

\section{Materials and Methods}

Pathogen sampling, isolation, and inoculum production. Winter canola leaves with leaf spot were collected from commercial fields, on-farm variety trials, and research plots from nine counties in Oklahoma and one county in southern Kansas from 2009 to 2013 (Fig. 1). Collections were mostly made in April during bloom stages of crop development. Most of the samples were taken in commercial fields planted with glyphosate-tolerant, open-pollenated cultivars whose blackleg reaction is largely unknown except that they appear to have quantitative or field resistance to canker development in adult plants. A small percentage of the acreage was planted and possibly sampled, particularly in Major County, with nonglyphosate tolerant hybrids from Europe that are described as having strong quantitative but not major gene resistance (D\&L Seeds, personal communication). Single pycnidia were removed from sporulating lesions with a sterile surgical blade and cultured on clarified V8 juice agar amended with streptomycin (100 ppm). Isolates were hyphal-tip purified at least twice and incubated for 12 to 15 days at $24^{\circ} \mathrm{C}$ under continuous fluorescent light until sporulation (Mengistu et al. 1991). For long-term storage, the fungus was grown on V8 juice agar overlaid with sterile filter paper. Small pieces of filter paper colonized with mycelia were stored dry at $4^{\circ} \mathrm{C}$ in sterile vials.

Inoculum of $L$. maculans was produced by collecting conidia from sporulating cultures on clarified V8 juice agar as described by Mengistu et al. (1991). Conidial suspensions were prepared by flooding plates with sterile distilled water, gently rubbing culture surfaces with a sterile spreader, and straining the suspensions through cheesecloth. Sporulating cultures were produced by spreading conidial suspensions over the surface of YPS ( $1 \mathrm{~g}$ of yeast extract, $1 \mathrm{~g}$ of peptone, $1 \mathrm{~g}$ of dextrose, $0.1 \mathrm{~g}$ of chloramphenicol, $0.2 \mathrm{~g}$ of zosyn, $0.025 \mathrm{~g}$ of rifampicin, $16 \mathrm{~g}$ of agar/liter distilled water) or V8 juice agar and incubating cultures at room temperature under continuous white fluorescent light. For pathogenicity tests, conidia were collected from 10to 15-day-old sporulating cultures that had a dense lawn of mature pycnidia with little mycelium (Balesdent et al. 1998). Spore suspensions were adjusted to $10^{6}$ spores $/ \mathrm{ml}$ using a hemocytometer. Aliquots of the spore suspensions were centrifuged and kept frozen until needed to produce new sporulating cultures (Mengistu et al. 1991).

Pathogenicity tests. Seeds of the following B. napus cultivars were obtained from the U.S. Department of Agriculture Germplasm Resources Information Network and increased in the greenhouse: Westar with no Rlm genes, Glacier harboring Rlm2 and Rlm3, Quinta harboring $R \operatorname{lm} 1$ (and possibly $R \operatorname{lm} 3$ or $R \operatorname{lm} 4$ ), and Jet Neuf harboring Rlm4 (Balesdent et al. 2001, 2002). Seeds were pregerminated on moist paper towels and seedlings with a 5- to $10 \mathrm{~mm}$-long radicle were transplanted into plastic flats fitted with 72-cell packs containing soilless growing media (vermiculite, sphagnum peat moss, coarse perlite, dolomitic limestone). Seedlings were maintained for 7 days in a growth chamber at $24^{\circ} \mathrm{C}, 80 \% \mathrm{RH}$, and continuous fluorescent light. Plants were watered as needed and nutrients were supplied by applying soluble fertilizer at $0.6,0.2$, and 0.4 g/liter of N-P-K, respectively, within the first week.

Seedlings were wounded 7 days after transplanting by puncturing each half of a cotyledon with a $200-\mu 1$ micropipette tip. Two wounds were made per cotyledon, totaling four per plant. Each wound was inoculated with a $5-\mu l$ droplet of conidial suspension adjusted to $10^{6} \mathrm{spores} / \mathrm{ml}$. Each isolate was inoculated onto eight plants of each differential cultivar, and inoculations for each isolate were repeated (Balesdent et al. 2005). Inoculated seedlings were placed in a dew chamber for 2 days at $24^{\circ} \mathrm{C}, 100 \% \mathrm{RH}$, and no light. Seedlings were moved back to the growth chamber for another 8 days. Emerging true 
leaves were removed every 2 to 3 days by pinching the growing tip of the seedlings to help the cotyledons remain green until disease severity was assessed (Mengistu et al. 1991).

The phenotypic interactions were scored 10 days after inoculation by assessing disease severity using the IMASCORE rating scale composed of six infection classes (ICs) proposed by Volke (1999) and used by Balesdent et al. (2001). IC1 to IC 3 correspond to isolates that produce a resistant reaction, and IC4 to IC6 correspond to isolates that produce a susceptible reaction. IC1 is the hypersensitive response, IC2 represents a larger ( 1.5 to $3 \mathrm{~mm})$ dark necrotic lesion, and IC3 is a nonsporulating lesion that is sharply delimited by a dark necrotic margin. IC4 to IC6 consist of spreading, gray-green lesions with no dark margins. IC4 has no sporulation, IC5 has a few pycnidia, and IC6 has abundant pycnidia.

Infection class scores on the four differentials were averaged by plant. Obvious outliers, cotyledons or plants that had no disease and appeared noninoculated compared with other replicate observations, were considered escapes and treated as missing data in the averages. Only $2.8 \%$ of the 4,455 inoculated plants were deemed escapes. The result of each isolate by cultivar interaction was averaged and classified as avirulent (IC $<4$ ) or virulent (IC $\geq 4$ ). An avirulent interaction implied the presence of the corresponding avirulence $(A v r)$ allele in the pathogen, whereas a virulent reaction implied the presence of a virulence ( $a v r$ ) allele. For isolate by cultivar interactions that were inconclusive, differential inoculations were repeated. Infection class scores were used to classify isolates to race as proposed by Balesdent et al. (2005). In this race classification, the Avr allele composition of each isolate was described by listing all of the Avr loci for which the isolate has been characterized and is avirulent.

Molecular characterization of isolates. Isolates were characterized for mating type, Leptosphaeria spp., and avirulence alleles AvrLm1, AvrLm6, and AvrLm4-7 (confers dual recognition for $R \operatorname{lm} 4$ and $R \operatorname{lm} 7)$ by PCR. Isolates $(n=102)$ were cultured on clarified V8 juice. Genomic DNA was extracted from semidried mycelia using the DNeasy 96 Plant Kit (Qiagen) following the manufacturer's recommendations and amplified using specific primers for targeted genes.

Leptosphaeria spp. were identified using the primer pair HV17 and HV26C, which amplifies the internal transcribed spacer (ITS) region (377 bp) specific for L. maculans (Mahuku et al. 1995) and the primer pair WV17S and 5.8S (237 bp) specific for L. biglobosa (Xue et al. 1992). Amplification of the mating-type (MAT) locus was used as a control for DNA quality and to confirm the identification of $L$. maculans. Specific primers for the two alternate forms of the MAT locus were used in a multiplex PCR (Cozijnsen and Howlett 2003). A 686-bp amplicon was produced for MAT1-1 isolates, and a 443-bp amplicon was produced for MAT1-2 isolates. PCR amplification of the species-specific ITS region, amplification of the MAT locus, and pathogenicity on Westar were used to differentiate L. maculans isolates from L. biglobosa.
In assessing the presence of avirulence alleles by PCR, the primer pair $A v r L m 1-F$ and $A v r L m 1-R$ was used to amplify a 695-bp fragment of the AvrLml gene (Van de Wouw et al. 2010). The primer set Avr47ext-Lo and Avr47ext-Up3 was used to amplify a 788-bp fragment of the AvrLm4-7 gene (Parlange et al. 2009). Finally, the primer set AvrLm6-F and AvrLm6-R was used to amplify a 751-bp fragment of AvrLm6 (Van de Wouw et al. 2010). PCR amplifications were carried out in $25-\mu 1$ reactions in a Techne TC-4000 Thermal Cycler (Techne Inc., Burlington, NJ). The PCR products were visualized by electrophoresis in $1.2 \%$ agarose gels in TAE buffer.

\section{Results}

Collection and identification of Leptosphaeria spp. The pathogen collection consisted of 102 isolates, with eight from 2009, two from 2010 (county of origin unknown), seven from 2011, 25 from 2012, and 60 from 2013. The ITS region for L. maculans and the MAT locus were not amplified for 12 of the 102 isolates. In addition, the ITS region for L. biglobosa was amplified for these 12 isolates. These isolates produced small necrotic spots and chlorosis on Westar that were different from the susceptible symptoms observed when inoculated with L. maculans. The 12 isolates identified as L. biglobosa were found in Kingfisher County, Oklahoma in 2011 and in Barber County, Kansas and Major County, Oklahoma in 2012. The rest of the isolates $(n=90)$, virulent on Westar and positive for the $L$. maculans ITS region and the MAT locus, were identified as L. maculans. Most of the isolates were collected in Barber and Grant counties (Fig. 1). Amplification and sequencing of a few isolates $(n=5$ of 90$)$ using general ITS primers (ITS1 and ITS4) confirmed the species as $L$. maculans. The MAT1-1 (47\%) and MAT1-2 (53\%) isolates occurred at similar frequencies in the population.

Avirulence alleles in $\boldsymbol{L}$. maculans. L. maculans isolates were characterized for avirulence alleles AvrLm1, AvrLm2,3, AvrLm4-7, and $A v r L m 6$ based on phenotype interaction on differentials harboring Rlm1, Rlm2, Rlm3, and Rlm4 and PCR amplification of AvrLm1, AvrLm4-7, and AvrLm6 (Table 1). The frequency of AvrLm1 was determined by the resistant phenotypic interaction on differential cultivar Quinta and by PCR. The frequencies of isolates that gave a resistant phenotype on Quinta $(35 \%)$ and produced the expected amplicon of AvrLml (34\%) were similar. The avirulence allele AvrLm 2 determined by a resistant phenotype on Glacier was found at a low frequency of $4 \%$. The avirulence alleles AvrLm4-7 and AvrLm6, identified by PCR, were present in all isolates of the population. All of the isolates except one were virulent on the differential Jet Neuf that harbors $R \operatorname{lm} 4$, indicating that $99 \%$ of the isolates had the AvrLm7 allele of the AvrLm4-7 dual recognition gene.

Race classification of $\boldsymbol{L}$. maculans isolates. The largest group of isolates $(57 \%)$ were virulent with infection class scores of $\geq 4$ on all four differentials (Table 1). The AvrLml fragment was not amplified in these isolates, but the AvrLm6 and AvrLm4-7 fragments were and they were classified as race $A v r L m 6-7$. There were five other isolates (6\%) that were also classified as race AvrLm6-7, but there were

Table 1. Races of Leptosphaeria maculans from winter canola in Oklahoma and Kansas during 2009 to 2013 classified by pathogenicity profiles on differentials harboring Rlm1, Rlm2,3, and Rlm4 and by PCR for avirulence alleles AvrLm1, AvrLm6, and AvrLm4-7

\begin{tabular}{|c|c|c|c|c|c|c|c|c|}
\hline \multirow[b]{2}{*}{ Isolates $(n)$} & \multirow[b]{2}{*}{ Westar $^{\mathbf{a}}$} & \multirow{2}{*}{$\frac{\text { Glacier }}{R \operatorname{lm} 2,3}$} & \multirow{2}{*}{$\frac{\text { Quinta }}{R \operatorname{lm} 1}$} & \multirow{2}{*}{$\frac{\text { Jet Neuf }}{R \operatorname{lm} 4}$} & \multicolumn{3}{|c|}{$\mathbf{P C R}^{\mathbf{b}}$} & \multirow[b]{2}{*}{ Race } \\
\hline & & & & & Avrl & Avr6 & Avr4-7 & \\
\hline 51 & V & V & V & V & - & + & + & Avr6-7 \\
\hline 5 & $\mathrm{~V}$ & V & A & $\mathrm{V}$ & - & + & + & Avr6-7 \\
\hline 5 & $\mathrm{~V}$ & V & $\mathrm{V}$ & $\mathrm{V}$ & + & + & + & Avrl-6-7 \\
\hline 24 & $\mathrm{~V}$ & V & A & $\mathrm{V}$ & + & + & + & Avrl-6-7 \\
\hline 1 & $\mathrm{~V}$ & V & $\mathrm{V}$ & A & - & + & + & Avr4-6-7 \\
\hline 2 & $\mathrm{~V}$ & A & A & $\mathrm{V}$ & + & + & + & Avr1-2-6-7 \\
\hline 1 & $\mathrm{~V}$ & A & A & $\mathrm{V}$ & - & + & + & Avr2-6-7 \\
\hline 1 & $\mathrm{~V}$ & A & $\mathrm{V}$ & $\mathrm{V}$ & - & + & + & Avr2-6-7 \\
\hline
\end{tabular}

a $\mathrm{V}=$ virulent on the differential cultivar (mean infection class score $\geq 4$ ) based on infection class scores ( 1 to 6 ), where 1 to 3 are resistant reactions that correspond to avirulence and 4 to 6 are susceptible reactions that correspond to virulence taken from 16 to 24 inoculated plants with four inoculated cotyledon lobes each per isolate (see the text); and $\mathrm{A}=$ isolate is avirulent on the differential cultivar (mean infection class score $<4$ ).

b Plus signs indicate amplification, and minus signs indicate no amplification of avirulence alleles with PCR 
discrepancies between virulence on Quinta $(R \operatorname{lm} 1)$ and PCR amplification of the AvrLml fragment. Four of the isolates had infection class scores just below the 4.0 considered virulent on Quinta. However, the AvrLml fragment was not amplified in these isolates. The fifth isolate clearly was avirulent on Quinta but also did not produce the expected PCR amplicon of AvrLm1.

The second largest group of isolates $(27 \%)$ were avirulent on Quinta and produced the expected AvrLml amplicon (Table 1). These isolates were virulent on the other differentials, produced the AvrLm4-7 and AvrLm6 amplicons, and were classified as race AvrLm1-6-7. Five isolates produced the AvrLm1 amplicon but were virulent on Quinta and were classified as AvrLm1-6-7.

The remaining isolates belonged to infrequently occurring races (Table 1). Two isolates were classified as race AvrLm1-2-6-7. One isolate was avirulent on both Glacier and Quinta but did not produce the AvrLm1 amplicon and was considered AvrLm2-6-7. Another isolate virulent on Glacier was classified as AvrLm2-6-7. Only one isolate was avirulent on Jet Neuf and was classified as AvrLm4-6-7.

The frequency of AvrLm 7 and Avrlm6 avirulence alleles was at or near $100 \%$ for every county sampled (Fig. 2A). The AvrLm4-7 allele was only found in one isolate from Noble County, Oklahoma. In contrast, variation was observed in frequencies of AvrLm1 and AvrLm2 (Fig. 2A) among counties. AvrLml was found in seven of the nine counties and occurred at low frequencies of $10 \%$ or less except for Blaine (25\%), Cotton (28\%), Grant (18\%), and Barber (21\%) counties. AvrLm2 was not found anywhere except for Grant County, where it occurred at a frequency of $7 \%$.

The frequency of races also varied with county sampled (Fig. 2B). Race AvrLm6-7 was found in all counties at frequencies of 33 to $100 \%$ (Fig. 2B). AvrLm1-6-7 was found in all counties except Major and Noble at frequencies of 17 to $67 \%$. The highest frequencies of race AvrLm1-6-7 were found in Blaine (67\%),

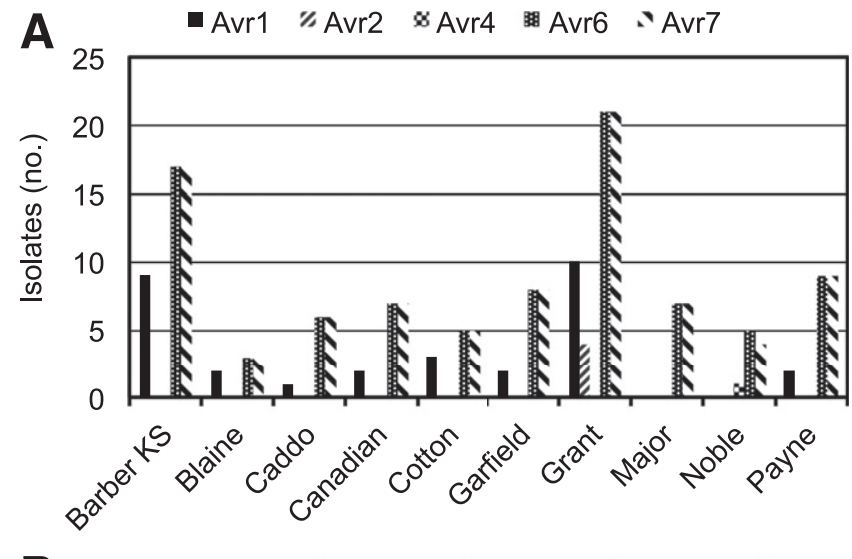

B
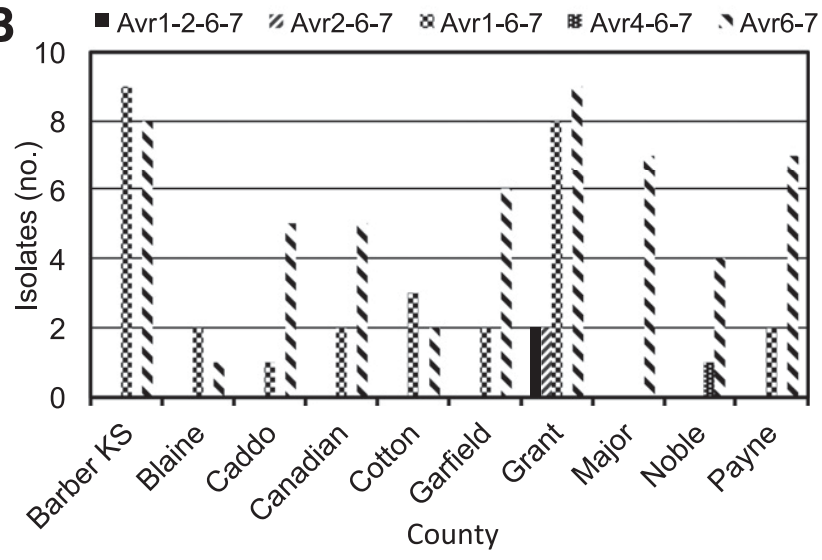

Fig. 2. Frequency of $\mathbf{A}$, avirulence alleles and $\mathbf{B}$, races, defined as the collection of avirulence alleles in an isolate of Leptosphaeria maculans, by geographic location (county) for winter canola sampled in Oklahoma and Kansas from 2009 to 2013 ( $n=88$; the geographic origin of two isolates included in this study was unknown).
Cotton (60\%), and Barber (53\%) counties. Races AvrLm1-2-6-7 and AvrLm2-6-7 were only found in Grant County at frequencies of $<10 \%$. Race AvrLm4-6-7 was only found in Noble County at a frequency of $20 \%$.

\section{Discussion}

L. maculans was recovered from all winter canola-growing regions of Oklahoma and Kansas sampled during the period of 2009 to 2013. Most of the isolates were collected in 2012 and 2013, which likely reflected prevailing environmental conditions. Isolates from 2009 were from the initial outbreak of the disease in the region. In 2010 and 2011, severe drought and excessive summer temperatures likely limited pseudothecial development on canola crop residues after harvest, blackleg development in the following crop, and resulting sample numbers. Sample numbers were highest for counties such as Barber and Grant, which had long canola cropping histories and short crop rotation intervals.

Using phenotyping on a limited differential set and PCR amplification of other known avirulence alleles, two predominant races were identified that were polymorphic only for Rlm1. All of the isolates had the avirulence alleles AvrLm6 and AvrLm4-7. AvrLm4 was only identified in a single isolate, indicating that the remaining isolates had the avrLm4-AvrLm7 allele of the dual recognition gene AvrLm4-7 (Parlange et al. 2009). In addition to the predominant races AvrLm1-6-7 and AvrLm6-7, the avirulence gene AvrLm2 was found in a few isolates. Although the diversity of races was low, both mating types (MAT1-1 and MAT1-2) were identified at similar frequencies in the population, suggesting a potential for development of new recombinants. The presence of both mating types supports observations in the field of pseudothecia and ascospore production on stubble left on the soil surface following canola production.

There were discrepancies observed for several isolates in evaluating the interaction of $R \operatorname{lml}$ and AvrLml. Some isolates $(n=6)$ were avirulent (IC $<4$ ) on Quinta but lacked the AvrLml amplicon, whereas others $(n=5)$ were virulent (IC $\geq 4)$ on Quinta but the PCR test produced the AvrLml amplicon. Therefore, the accuracy of the resulting phenotypic interactions between the differential Quinta and local isolates was not always supported by PCR amplification of AvrLm1. AvrLm1 was found in 33\% $(n=30)$ of the local population of $L$. maculans when determined by PCR amplification. A similar percentage $(34 \%)$ of the isolates $(n=31)$ had IC scores of $<4$ on Quinta. The discrepant results did not greatly alter conclusions about the frequency of $A v r L m 1$ in the population, but there was uncertainty about the specific allele composition of approximately $12 \%$ of the isolates. The PCR results with the primers used in this study (Van de Wouw et al. 2010) were confirmed for isolates in question with primers reported by Gout et al. (2006). These inconsistencies related to Rlml and AvrLml may have resulted from the differential cultivar Quinta being a heterogeneous genotype containing more than one resistance gene. Others have reported that Quinta harbors Rlml (Ansan-Melayah et al. 1995) and, depending on the seed lot, $R \operatorname{lm} 3$ (Kutcher et al. 2010a) or Rlm4 resistance genes (Balesdent et al. 2001). Thus, Quinta may not be an ideal differential cultivar for characterization of L. maculans isolates. Instead, other available differential cultivars that harbor $R \operatorname{lm} 1$ in combination with another Rlm gene, like cultivars Columbus $(R \operatorname{lm} 1, R \operatorname{lm} 3)$ (Balesdent et al. 2002) or Cooper (Rlm1, Rlm4) (Dilmaghani et al. 2009), have been used in other studies but were not made available for use in this study. Interactions where resistant phenotypes were observed on Quinta in the absence of the AvrLm1 amplicon could also be attributable to the presence of additional Rlm genes not assessed in this study or the presence of a novel Rlm gene not yet discovered or described (Dilmaghani et al. 2009). Finally, it is possible that isolates in our population may have unique polymorphisms in the AvrLml locus, rendering it nonfunctional (PCR amplification but virulent), or DNA sequence variation at the primer annealing sites (no PCR amplification but avirulent). Gout et al. (2007) reported that virulence on Rlml (avrLml) was attributable mostly to deletion of the entire AvrLm1 locus, except for isolates from one region in France where 
nearly $10 \%$ of avrLm1 isolates could be amplified by PCR or hybridized with AvrLm1-derived probes.

The avirulence genes AvrLm 2 and AvrLm3 were evaluated by phenotypic interaction on Glacier, a differential cultivar with both $R \operatorname{lm} 2$ and Rlm3 resistance genes. Therefore, the resistant response on Glacier in itself does not allow for the two corresponding avirulence genes to be distinguished. It is likely that the resistant responses on Glacier were a result of interactions with AvrLm2 because it was reported that AvrLm3 expression is masked by a functional AvrLm7 gene (Plissonneau et al. 2016, 2017). Large-scale surveys and phenotyping of isolates in France and other parts of Europe from 2000 to 2003, prior to the release of $R \operatorname{lm} 7$ cultivars, showed that $99 \%$ of isolates were avirulent on $\operatorname{Rlm} 7$ and virulent on $R \operatorname{lm} 3$ (Balesdent et al. 2006). Isolates in this study with resistant responses on Glacier were thus classified as AvrLm2 races. The low frequency of $A v r L m 2$ in our population suggests that the resistance gene $R \operatorname{lm} 2$ is not expected to be effective in this region. However, virulence to $R \operatorname{lm} 7$ restores the $A v r L m 3$ expression, which may make $R \operatorname{lm} 3$ resistance important in the future.

It would have been ideal to work with a set of differential cultivars that each possess a single resistance gene, to use an extended number of differentials with complementary combinations of Rlm genes, and to include differentials for additional avirulence not evaluated in this study (Balesdent et al. 2005; Fernando et al. 2018). However, additional differentials were not made available for this study. Near isogenic lines have been developed with $R \operatorname{lm} 1, R \operatorname{lm} 2, R \operatorname{lm} 3$, and $R \operatorname{lm} 4$ (Larkan et al. 2016). Quinta has $R \operatorname{lm} 1$ and either Rlm 3 or Rlm4 and in theory should be a good differential for $A v r L m 1$ for the population described in this study. AvrLm3 is suppressed by AvrLm7, which was present in all of the isolates evaluated in this study. Additionally, AvrLm4 was found only in one isolate, so recognition of AvrLm4 should not confound AvrLml expression in the local population. Similarly, the cultivar Glacier $(R \operatorname{lm} 2,3)$ should be an effective differential for AvrLm2 in the local population because of the AvrLm4-7 mediated $R \operatorname{lm} 3$ epistasis described above. The cultivar Jet Neuf $(R \operatorname{lm} 4)$ was effective for discriminating AvrLm4 (Balesdent et al. 2001). We also used the B. juncea 'Aurea' $(R \operatorname{lm} 5,6)$ (Balesdent et al. 2002). A subset of isolates was tested on Aurea and all produced an avirulent reaction. However, because AvrLm6 was present in all isolates, Aurea was not a good differential for AvrLm5 and all isolates were not tested on it. In summary, we should have been able to discriminate AvrLm1, AvrLm2, and AvrLm4 unambiguously by interaction phenotype in this study.

The avirulence allele AvrLm4, identified by phenotypic interaction on Jet Neuf, was found at the lowest frequency. The near universal virulence on $\operatorname{Rlm} 4$ may be attributable to repeated exposure of isolates to cultivars with Jet Neuf in their genetic background. Jet Neuf was used as a parent in the development of the winter canola cultivar Wichita, which was one of the first cultivars grown in Oklahoma and Kansas beginning about 15 years ago (Rife et al. 2001; Stamm et al. 2012). Wichita was one of the first cultivars with acceptable winter hardiness. Resistance dependent on Rlm4 has also largely been rendered ineffective in Europe because of a point mutation that produces a single amino change in the avirulence protein that circumvents Rlm4-mediated resistance (Parlange et al. 2009).

The avirulence alleles AvrLm6 and AvrLm 7 identified by PCR and pathogenicity on Jet Neuf $(R \operatorname{lm} 4)$ represented the highest frequency $(100 \%)$ of avirulence alleles in all of the counties sampled. Since AvrLm6 and AvrLm 7 were present in all isolates and currently appear to be universal in the population, cultivars with the corresponding resistance genes $R \operatorname{lm} 6$ or $R \operatorname{lm} 7$ should be broadly effective if deployed in Oklahoma and Kansas at this time. Rlm6 has been introgressed into $B$. napus from B. juncea (Chèvre et al. 1997). Therefore, the fact that all isolates from the collection carry avirulence allele AvrLm6 is not surprising, as this resistance gene had been used only in research in Europe (Chèvre et al. 1997; Kutcher et al. 2010b). Only a few canola cultivars with $R \operatorname{lm} 6$, designated by an "MX" trademark, were developed in Europe (Brun et al. 2010). These were planted in experimental plots and the resistance was lost relatively quickly when Rlm6 cultivars were deployed in genetic backgrounds that lacked accompanying multigenic resistance and when $R \operatorname{lm} 6$ cultivars were grown in infested stubble from Rlm6 varieties (Brun et al. 2010). Because of a similar loss of $R l m 1$-mediated resistance in commercial fields about 15 years earlier, and the close chromosomal linkage of Rlm1 and Rlm6 (Fudal et al. 2007), Rlm6 resistance was never released in commercial cultivars or hybrids (Brun et al. 2010). Therefore, it is unlikely that the population of L. maculans in Oklahoma and Kansas has been previously exposed to Rlm6 resistance.

Deployment of $R \operatorname{lm} 7$ in genetic backgrounds with quantitative resistance along with crop rotation is currently the principal method of blackleg control in Europe (Brun et al. 2010; Plissonneau et al. 2017). In experimental plots of $R \operatorname{lm} 7$ cultivars grown under severe selection pressure similar to the Rlm6 studies of Brun et al. (2010), the frequency of arv $\operatorname{Lm} 7$ isolates virulent on $\operatorname{Rlm} 7$ increased to $36 \%$ in 4 years via diverse molecular events including repeat induced point mutations, point mutations, or gene deletions (Daverdin et al. 2012). The increase in arvLm7 in field isolates in France has been slower, reaching only $11 \%$ by 2013 (Plissonneau et al. 2017). However, virulence toward $\operatorname{Rlm} 7$ has been largely offset by the epistatic expression of AvrLm3 (Plissonneau et al. 2016). In Oklahoma and Kansas, hybrids from Europe with $R \operatorname{lm} 7$ have been grown experimentally in performance trials but have not been marketed commercially. Therefore, it is not surprising that $A v r L m 7$ isolates were found at a high frequency in this survey.

Until this study, there was little known about the L. maculans race structure in Oklahoma and Kansas. Surveys to determine the race structure of L. maculans in the United States have been reported from Georgia in the southeastern United States and North Dakota in the northern part of the country (Dilmaghani et al. 2009; Fernando et al. 2018). The avirulence allele and race structure reported here are similar to those reported in Georgia and in Western Australia except for AvrLm1, which occurred at higher frequencies of 60 to $80 \%$, respectively (Dilmaghani et al. 2009). Isolates from Europe also generally lacked AvrLm2 and AvrLm3, and AvrLm1 and AvrLm4 to a lesser extent, whereas AvrLm6 and AvrLm7 were prevalent (Balesdent et al. 2006). The population in this study had less diverse avirulence alleles than reported in Canada in 2018, where AvrLm2 and AvrLm4 were present at frequencies of $>60 \%$ (Fernando et al. 2018). Identification of the $A v r$ alleles in the local $L$. maculans population provided relevant information about the Rlm genes that would be the most effective in managing blackleg in the region. However, sustainable deployment of effective resistance genes should be in combination with strong quantitative resistance and crop rotation programs (Brun et al. 2010).

\section{Literature Cited}

Ansan-Melayah, D., Balesdent, M. H., Buée, M., and Rouxel, T. 1995. Genetic characterization of AvrLml, the first avirulence gene of Leptosphaeria maculans. Phytopathology 85:1525-1529.

Balesdent, M. H., Attard, A., Ansan-Melayah, D., Delourme, R., Renard, M., and Rouxel, T. 2001. Genetic control and host range of avirulence toward Brassica napus cultivars Quinta and Jet Neuf in Leptosphaeria maculans. Phytopathology 91:70-76.

Balesdent, M. H., Attard, A., Kühn, M., and Rouxel, T. 2002. New avirulence genes in the phytopathogenic fungus Leptosphaeria maculans. Phytopathology 92 1122-1133.

Balesdent, M. H., Barbetti, M., Li, H., Sivasithamparam, K., Gout, L., and Rouxel, T. 2005. Analysis of Leptosphaeria maculans race structure in a worldwide collection of isolates. Phytopathology 95:1061-1071.

Balesdent, M. H., Fudal, I., Ollivier, B., Bally, P., Grandaubert, J., Eber, F., Chévre, A., Leflon, M., and Rouxel, T. 2013. The dispensable chromosome of Leptosphaeria maculans shelters an effector gene conferring avirulence towards Brassica rapa. New Phytol. 198:887-898.

Balesdent, M. H., Jedryczka, M., Jain, L., Mendes-Pereira, E., Bertrandy, J., and Rouxel, T. 1998. Conidia as a substrate for internal transcribed spacer-based PCR identification of members of the Leptosphaeria maculans species complex. Phytopathology 88:1210-1217.

Balesdent, M. H., Louvard, K., Pinochet, X., and Rouxel, T. 2006. A large-scale survey of races of Leptosphaeria maculans occurring on oilseed rape in France. Eur. J. Plant Pathol. 114:53-65.

Brun, H., Chèvre, A. M., Fit, D. D. L., Powers, S., Besnard, A. L., Ermel, M. Huteau, V., Marquer, B., Eber, F., Renard, F., and Andrivon, D. 2010 Quantitative resistance increases the durability of qualitative resistance to Leptosphaeria maculans in Brassica napus. New Phytol. 185:285-299.

Chèvre, A. M., Barret, P., Eber, F., Dupuy, P., Brun, H., Tanguy, X., and Renard, M. 1997. Selection of stable Brassica napus-B. juncea recombinant lines resistant to blackleg (Leptosphaeria maculans). 1. Identification of molecular 
markers, chromosomal and genomic origin of the introgression. Theor. Appl. Genet. 95:1104-1111.

Cozijnsen, A., and Howlett, B. 2003. Characterisation of the mating-type locus of the plant pathogenic ascomycete Leptosphaeria maculans. Curr. Genet. 43: 351-357.

Cunningham, G. H. 1927. Dry-rot of swedes and turnips: Its cause and control. New Zeal. Dept. Agr. Bull. 133.

Daverdin, G., Rouxel, T., Gout, L., Aubertot, J. N., Fudal, I., Meyer, M., Parlange, F., Carpezat, J., and Balesdent, M. H. 2012. Genome structure and reproductive behavior influence the evolutionary potential of a fungal phytopathogen. PLoS Pathog 8:e1003020.

del Río Mendoza, L. E., Nepal, A., Bjerke, J. M., Boyles, M., and Peeper, T. 2011. Identification of Leptosphaeria maculans pathogenicity group 4 causing blackleg on winter canola in Oklahoma. Plant Dis. 95:614.

del Río Mendoza, L. E., Nepal, A., and Markell, S. 2012. Outbreak of blackleg of canola in North Dakota is caused by new pathogenicity groups. Plant Health Progress. doi:10.1094/PHP-2012-0410-01-RS

Delourme, R., Chevre, A., Brun, H., Rouxel, T., Balesdent, M. H., Dias, J., Salisbury, P., Renard, M., and Rimmer, S. 2006. Major gene and polygenic resistance to Leptosphaeria maculans in oilseed rape (Brassica napus). Eur. J. Plant Pathol. 114:41-52.

Delourme, R., Pilet-Nayel, M., Archipiano, M., Horvais, R., Tanguy, X., Rouxel, T., Brun, H., Renard, M., and Balesdent, M. H. 2004. A cluster of major specific resistance genes to Leptosphaeria maculans in Brassica napus. Phytopathology 94:578-583.

Dilmaghani, A., Balesdent, M. H., Didier, J., Wu, C., Davey, J., Barbetti, M., Li, H., Moreno-Rico, O., Phillips, D., and Despeghel, J. 2009. The Leptosphaeria maculans-Leptosphaeria biglobosa species complex in the American continent. Plant Pathol. 58:1044-1058.

Fernando, W. G. D., Zhang, X., Selin, C., Zou, Z., Liban, S. H., McClarin, D. L., Kubinec, A., Parks, P. S., Rashid, M. H., Rasanie, K., Padmathilake, E., Rong, L., Yang, C., Gnanech, B. N., and Huang, S. 2018. A six-year investigation of the dynamics of avirulence allele profiles, blackleg incidence, and mating type alleles of Leptoshpaeria maculans populations associated with canola crops in Manitoba, Canada. Plant Dis. 102:790-798.

Fudal, I., Ross, S., Gout, L., Blaise, F., Kuhn, M. L., Eckert, M. R., Cattolico, L., Bernard-Samain, S., Balesdent, M. H., and Rouxel, T. 2007. Heterochromatinlike regions as ecological niches for avirulence genes in the Leptosphaeria maculans genome: Map-based cloning of AvrLm6. Mol. Plant Microbe Interact. 20:459-470.

Ghanbarnia, K., Fernando, W. G. D., and Crow, G. 2011. Comparison of disease severity and incidence at different growth stages of naturally infected canola plants under field conditions by pycniospores of Phoma lingam as a main source of inoculum. Can. J. Plant Pathol. 33:355-363.

Ghanbarnia, K., Ma, L., Larkin, N. J., Haddadi, P., Fernando, W. G. D., and Borhan, M. H. 2018. Leptosphaeria maculans AvrLm9: A new player in the game of hide and seek with AvrLm4-7. Mol. Plant Pathol. 19:1754-1764.

Gout, L., Fudal, I., Kuhn, M. L., Blaise, F., Eckert, M., Cattolico, L., Balesdent, M. H., and Rouxel, T. 2006. Lost in the middle of nowhere: The AvrLm1 avirulence gene of the Dothideomycete Leptosphaeria maculans. Mol. Microbiol. 60:67-80.

Gout, L., Kuhn, M. L., Vincenot, L., Bernard-Samain, S., Cattolico, L., Barbetti, M., Moreno-Rico, O., Balesdent, M. H., and Rouxel, T. 2007. Genome structure impacts molecular evolution at the AvrLm1 avirulence locus of the plant pathogen Leptosphaeria maculans. Environ. Microbiol. 9:2978-2992.

Guo, X. W., and Fernando, W. G. D. 2005. Seasonal and diurnal patterns of spore dispersal by Leptoshpaeria maculans in relation to environmental conditions. Plant Dis. 89:97-104.

Hayden, H. L., Cozijnsen, A. J., and Howlett, B. J. 2007. Microsatellite and minisatellite analysis of Leptosphaeria maculans in Australia reveals regional genetic differentiation. Phytopathology 97:879-887.

Kutcher, H., Balesdent, M. H., Rimmer, S., Rouxel, T., Chevre, A., Delourme, R., and Brun, H. 2010a. Frequency of avirulence genes in Leptosphaeria maculans in western Canada. Can. J. Plant Pathol. 32:77-85.

Kutcher, H., Yu, F., and Brun, H. 2010b. Improving blackleg disease management of Brassica napus from knowledge of genetic interactions with Leptosphaeria maculans. Can. J. Plant Pathol. 32:29-34.

Kutcher, H. R., Keri, M., McLaren, D. L., and Rimmer, S. R. 2007. Pathogenic variability of Leptosphaeria maculans in western Canada. Can. J. Plant Pathol. 29:388-393.

Larkan, N. J., Lydiate, D. J., Parkin, I. A. P., Nelson, M. N., Epp, D. J., Cowling, W. A., Rimmer, S. R., and Borhan, M. H. 2013. The Brassica napus blackleg resistance gene LepR3 encodes a receptor-like protein triggered by the Leptosphaeria maculans effector AvrLm1. New Phytol. 197:595-605.

Larkan, N. J., Ma, L., and Borhan, M. H. 2015. The Brassica napus receptor-like protein RLM2 is encoded by a second allele of the LepR3/Rlm2 blackleg resistance locus. Plant Biotechnol. J. 13:983-992.
Larkan, N. J., Yu, F., Lydiate, D. J., Rimmer, S. R., and Borhan, M. H. 2016. Single R gene introgression lines for accurate dissection of the BrassicaLeptosphaeria pathosystem. Front. Plant Sci. 7:1771.

Li, H., Sivasithamparam, K., and Barbetti, M. 2003. Breakdown of a Brassica rapa subsp. sylvestris single dominant blackleg resistance gene in B. napus rapeseed by Leptosphaeria maculans field isolates in Australia. Plant Dis. 87:752.

Mahuku, G. S., Goodwin, P. H., and Hall, R. 1995. A competitive polymerase chain reaction to quantify DNA of Leptosphaeria maculans during blackleg development in oilseed rape. Mol. Plant Microbe Interact. 8:761-767.

Marcroft, S. J., Elliott, V. L., Cozijnsen, A. J., Salisbury, P. A., Howlett, B. J., and Van de Wouw, A. P. 2012. Identifying resistance genes to Leptosphaeria maculans in Australian Brassica napus cultivars based on reactions to isolates with known avirulence genotypes. Crop Pasture Sci. 63:338-350.

Mendes-Pereira, E., Balesdent, M. H., Brun, H., and Rouxel, T. 2003. Molecular phylogeny of the Leptosphaeria maculans-L. biglobosa species complex. Mycol. Res. 107:1287-1304.

Mengistu, A., Rimmer, S., Kock, E., and Williams, P. H. 1991. Pathogenicity grouping of isolates of Leptosphaeria maculans on Brassica napus cultivars and their disease reaction profiles on rapid-cycling brassicas. Plant Dis. 75: 1279-1282.

Parlange, F., Daverdin, G., Fudal, I., Kuhn, M. L., Balesdent, M. H., Blaise, F., Grezes-Besset, B., and Rouxel, T. 2009. Leptosphaeria maculans avirulence gene AvrLm4-7 confers a dual recognition specificity by the Rlm4 and $R \operatorname{lm} 7$ resistance genes of oilseed rape, and circumvents Rlm4-mediated recognition through a single amino acid change. Mol. Microbiol. 71:851-863.

Petrie, G. 1978. Occurrence of a highly virulent strain of blackleg (Leptosphaeria maculans) on rape in Saskatchewan. Canadian Plant Dis. Surv. 58:21-25.

Plissonneau, C., Blaise, F., Ollivier, B., Lefton, M., Carpezat, J., Rouxel, T., and Balesdent, M.-H. 2017. Unusual evolutionary mechanisms to escape effectortriggered immunity in the fungal phytopathogen Leptosphaeria maculans. Mol. Ecol. 26:2183-2198

Plissonneau, C., Daverdin, G., Ollivier, B., Blaise, F., Degrave, A., Fudal, I., Rouxel, T., and Balesdent, M.-H. 2016. A game of hide and seek between the avirulence genes AvrLm4-7 and AvrLm3 in Leptosphaeria maculans. New Phytol. 209:1613-1624.

Plissonneau, C., Rouxel, T., Chèvre, A. M., Van de Wouw, A. P., and Balesdent, M. H. 2018. One gene-one name: The AvrLmJ1 avirulence gene of Leptosphaeria maculans is AvrLm5. Mol. Plant Pathol. 19:1012-1016.

Rife, C. L., Auld, D. L., Sunderman, H. D., Heer, W. F., Baltensperger, D. D., Nelson, L. A., and Johnson, D. L., Bordovsky, D., and Minor, H. C. 2001 Registration of 'Wichita' rapeseed. Crop Sci. 41:263-264.

Rimmer, S. R., and van den Berg, C. G. J. 2007. Blackleg (Phoma stem canker). Pages 19-23 in: Compendium of Brassica Diseases. S. R. Rimmer, V. I. Shattuck, and L. Buchwaldt, eds. American Phytopathological Society, St. Paul, MN.

Rouxel, T., and Balesdent, M. H. 2005. The stem canker (blackleg) fungus, Leptosphaeria maculans, enters the genomic era. Mol. Plant Pathol. 6:225-241.

Rouxel, T., Penaud, A., Pinochet, X., Brun, H., Gout, L., Delourme, R., Schmit, J., and Balesdent, M. H. 2003. A 10-year survey of populations of Leptosphaeria maculans in France indicates a rapid adaptation towards the Rlm1 resistance gene of oilseed rape. Eur. J. Plant Pathol. 109:871-881.

Shoemaker, R. A., and Brun, H. 2001. The teleomorph of the weakly aggressive segregate of Leptosphaeria maculans. Can. J. Bot. 79:412-419.

Stamm, M., Berrada, A., Buck, J., Cabot, P., Claassen, M., Cramer, G., Dooley, S. J., Godsey, C., Heer, W., and Holman, J. 2012. Registration of 'Riley' winter canola. J. Plant Regist. 6:243-245.

Van de Wouw, A. P., Cozijnsen, A. J., Hane, J. K., Brunner, P. C., McDonald, B. A., Oliver, R. P., and Howlett, B. J. 2010. Evolution of linked avirulence effectors in Leptosphaeria maculans is affected by genomic environment and exposure to resistance genes in host plants. PLoS Pathog 6:e1001180.

Van de Wouw, A. P., Lowe, R. G. T., Elliott, C. E., Dubois, D. J., and Howlett, B. J. 2014. An avirulence gene, AvrLmJ1, from the blackleg fungus, Leptosphaeria maculans, confers avirulence to Brassica juncea cultivars. Mol. Plant Pathol. 15: 523-530.

Vincenot, L., Balesdent, M., Li, H., Barbetti, M., Sivasithamparam, K., Gout, L., and Rouxel, T. 2008. Occurrence of a new subclade of Leptosphaeria biglobosa in Western Australia. Phytopathology 98:321-329.

Volke, B. 1999. Leptosphaeria maculans, der Erreger der Wurzelhals- und Stengelfäule an Raps: Verbreitung verschiedener Pathogenitätsgruppen in Europa, Quantifizierung des Befalls und Schadwirkung im Freiland. PhD thesis, Institut für Pflanzenpathologie und Pflanzenschutz, Universität Göttingen, Göttingen, Germany.

West, J., Balesdent, M. H., Rouxel, T., Narcy, J., Huang, Y. J., Roux, J., Steed, J., Fitt, B., and Schmit, J. 2002. Colonization of winter oilseed rape tissues by $\mathrm{A} / \mathrm{Tox}+$ and $\mathrm{B} / \mathrm{Tox} 0$ Leptosphaeria maculans (Phoma stem canker) in France and England. Plant Pathol. 51:311-321.

Xue, B., Goodwin, P. H., and Annis, S. L. 1992. Pathotype identification of Leptosphaeria maculans with PCR and oligonucleotide primers from ribosomal internal transcribed spacer sequences. Physiol. Mol. Plant Pathol. 41:179-188. 